\title{
POLIITICAS PÚBLICAS DE DESENVOLVIMENTO LOCAL E ADENSAMENTO DE CAPITAL SOCIAL: ANÁLISE DO PROGRAMA DE AQUISIÇÃO DE ALIMENTOS (PAA) EM QUATRO MUNICÍPIOS DE MINAS GERAIS*
}

\author{
PUBLIC POLICIES OF LOCAL DEVELOPMENT AND SOCIAL \\ CAPITAL DENSIFICATION: ANALYSIS OF THE FOOD ACQUISITION \\ PROGRAM (FPA) IN FOUR MUNICIPALITIES OF MINAS GERAIS
}

Data de submissão: 02/01/2015 Aceite: $11 / 06 / 2015$

Gustavo Leonardo Simão ${ }^{1}$ Alan Ferreira de Freitas ${ }^{2}$ Edson Arlindo Silva ${ }^{3}$

Bianca Ribeiro de Nardi Bastos ${ }^{4}$ Rafael Junior dos Santos F. Salgado ${ }^{5}$ Nora Beatriz Presno Amodeo (in memoriam)

\section{RESUMO}

O artigo analisou a eficácia do Programa de Aquisição de Alimentos (PAA), enquanto política pública de desenvolvimento local, em adensar o nível de capital social em quatro municípios do estado de Minas Gerais. Os dados foram coletados através da realização de entrevistas presenciais semiestruturadas com os diversos seguimentos de atores envolvidos na implementação e operacionalização do PAA, sendo posteriormente analisados pelas categorias operacionais de capital social previamente delimitado. Os principais resultados indicaram que as regiões analisadas possuem baixos níveis de capital social. Ademais, a existência de vieses operacionais na concepção e implementação do PAA, notavelmente em relação à deficiência na comunicação governamental junto aos atores envolvidos e ao funcionamento limitado das organizações coletivas, favorece a perenização do status quo. Assim, o modelo "moderno" de intervenção governamental, advindo com o PAA, não se mostra transformador, em relação ao desenvolvimento local, nos municípios pesquisados. Tal cenário, contudo, pode ser alterado quando há o apoio do poder público municipal e a existência de lideranças locais entre os beneficiários.

Palavras-chave: beneficiários, eficácia, política pública

\footnotetext{
* Os autores agradecem o apoio financeiro do Conselho Nacional de Desenvolvimento Científico e Tecnológico (CNPq) para a realização da pesquisa. 1 Possui graduação em Gestão de Cooperativas pela Universidade Federal de Viçosa, UFV. Mestrado em Administração pela Universidade Federal de Viçosa, UFV. Doutorado em andamento em Administração pela Universidade Federal de Lavras, UFLA. Lavras. Minas Gerais. Brasil. E-mail: gustavosimao@posgrad.ufla.br

2 Possui graduação em Gestão de Cooperativas, mestrado em Extensão Rural e doutorado em andamento em Extensão Rural pela Universidade Federal de Viçosa, UFV. Atualmente é professor efetivo do Departamento de Administração e Contabilidade da UFV e membropesquisador do Observatório Mineiro do Cooperativismo. Vicosa. Minas Gerais. Brasil. E-mail: alan.freitas@ufv.br

3 Possui bacharelado em Administração pela Universidade Federal de Viçosa, mestrado em Extensão Rural pelo Departamento de Economia Rural da Universidade Federal de Viçosa e doutorado em Administração pela Universidade Federal de Lavras. Pós-Doutorando em Administração Pela Universidade de São Paulo - USP (2017). Atualmente é Consultor Ad hoc \& Pesquisador-Bolsista de Produtividade junto ao Conselho Nacional de Desenvolvimento Científico e Tecnológico (CNPq). Ituiutaba. Minas Gerais. Brasil. E-mail: edsonsilva@ufv.br 4 Graduanda em Administração pela Universidade Federal de Viçosa. Viçosa. Minas Gerais. Brasil. E-mail: biancadnbastos@gmail.com 5 Possui bacharelado em Gestão do Agronegócio pela Universidade Federal de Viçosa, mestrado em Administração pela Universidade Federal de Viçosa e Doutorando em Administração pela Universidade Federal do Rio Grande do Norte. Viçosa. Minas Gerais. Brasil. E-mail: rafa.salgad@gmail.com
} 


\begin{abstract}
The paper analyzed the effectiveness of the Food Acquisition Program (FPA) as a public policy of local development, in densify the level of social capital in four cities in the state of Minas Gerais. Data was collected by conducting semi-structured interviews with several segments of actor involved in the implementation and operation of the FPA, subsequently analyzed by operating categories of social capital previously defined. Results indicated that the analyzed regions have low levels of social capital. Moreover, the existence of operational biases in the design and implementation of the FPA, notably in relation to deficiency in government communication among all the actors involved and the limited function of collective organizations, favors the perpetuation of the status quo. Thus, the modern model of the government intervention, arising with implementation the FPA, not have been transformer in relation to local development, in the cities studied. This scenario, however, can be changed when there is support from the municipal government and the existence of local leaders among the beneficiaries.
\end{abstract}

Keywords: beneficiaries, efficacy, public policy

\title{
1 INTRODUÇÃO
}

O conceito de desenvolvimento local, entendido como a busca por maior qualidade de vida por meio do protagonismo dos próprios atores locais, tem favorecido a inclusão da sociedade civil nas intervenções governamentais. Diante dessa nova concepção de desenvolvimento, as políticas públicas passam a ser cada vez mais pautadas pelo enfoque emancipatório, e a população, de mero agente passivo, é considerada como parceira dos governos.

No caso brasileiro, isso se deu principalmente por meio da descentralização. Que é percebida tanto em relação à inclusão do cidadão na coprodução das intervenções governamentais a ele destinadas, como também no compartilhamento das responsabilidades com os distintos níveis governamentais, de modo que os estados e municípios passam a compartilhar diversas responsabilidades com o governo central. Destarte, ao delegar responsabilidades aos cidadãos, as características socioculturais locais passam a ser variáveis intervenientes à eficácia das intervenções.

Diante disso, são cada vez mais frequentes as discussões inerentes ao impacto e à influência que o capital social possui nos resultados dessas ações. O conceito de capital social, apesar de ser considerado por vezes polissêmico, devido à variedade de autores e enfoques em que é empregado, foi entendido neste trabalho, como a capacidade de engajamento para trabalhos coletivos, o grau das redes sociais e o grau da participação comunitária e política da população local.

Contudo, a forma de criação e/ou adensado de capital social suscita discussões, notavelmente no que diz respeito à dicotomia cultura/estrutura. No âmbito da estrutura, naquelas localidades onde não se evidenciam aspectos socioculturais que caracterizam a alta formação de capital social, o Estado, a partir de algumas iniciativas, poderia induzir ao seu surgimento, por meio da criação de um processo sinérgico de relacionamento com a sociedade.

Pela vertente culturalista, que preza pelo acúmulo de capital social ao longo do tempo, advoga-se que de nada adiantaria esforços para o desenvolvimento local por meio de práticas coletivas se não houver capital social suficientemente desenvolvido que exerça influência na sinergia entre os atores locais.

Partindo dessas considerações, buscou-se com este artigo analisar a implementação e operacionalização do Programa de Aquisição de Alimentos (PAA) notavelmente em relação às implicações desse contexto para a criação de um cenário propício ao adensamento do capital social em regiões pobres. A questão central respondida pela pesquisa é: O Estado por meio do PAA, como política pública de desenvolvimento local coproduzida, consegue criar um cenário propício ao adensamento de capital social em regiões pobres? 


\section{POLÍTICAS PÚBLICAS E DESENVOLVIMENTO LOCAL}

Para Farah (2001, p. 121), uma "característica central das políticas sociais vigentes no Brasil até os anos 1980 consistia na exclusão da sociedade civil do processo de formulação das políticas, da implementação dos programas e do controle da ação governamental". Contudo, com a emergência das novas concepções de desenvolvimento, no final dos anos de 1980, houve a tendência de descentralização das ações governamentais, com uma nova concepção de relacionamento entre as distintas esferas governamentais, e dessas com os potenciais beneficiários.

Passador e Passador (2010) salientam que, com as mudanças ideológicas ocorridas, o enfoque do desenvolvimento passa a ser local, tomado de forma endógena, devendo para isso mobilizar as potencialidades locais (quebrar dependências e inércias), conciliando o enfoque econômico, de modo a incentivar e a fortalecer atividades viáveis e competitivas, com fatores socioeconômicos, tecnológicos e políticos. Ressalva deve ser feita, conforme ressalta Buarque (2002), aos aspectos políticos, que sofreram pressões para mudanças institucionais que aumentassem a governabilidade, a governança e a participação da população.

Appendini e Nuijten $(2002$, p.72) relataram que "as políticas intervencionistas dão passo a políticas focadas na capacitação e devolução de poder para fazer da população parceiros ativos nos esforços de desenvolvimento". A incorporação da participação dos cidadãos, somada à intersetorialidade, na elaboração e implementação das intervenções governamentais no contexto dessa nova abordagem de desenvolvimento torna-se uma prerrogativa cada vez mais premente.

A construção de políticas públicas voltadas para o desenvolvimento local, principalmente aquelas de cunho social, cria então novos desafios para os gestores públicos, sendo a descentralização o principal gerador destes desafios. Discorrendo a respeito das vantagens da descentralização das ações governamentais, Tendler (1998), a partir de estudos realizados em países da América Latina, principalmente no Brasil, relata que governos centrais não são os mais hábeis em atender às demandas dos usuários dos serviços públicos, inclusive no tocante às demandas da população mais pobre.

Para Ferrarini (2012, p. 237), um dos principais desafios das políticas públicas nesse novo contexto, além daqueles inerentes à intersetorialidade, "é a participação radicalizada e direta da comunidade como cogestora dos programas desenvolvidos no território, indo além dos avanços materiais e ativando o exercício da cidadania". Diante dessa nova tendência de administração pública, somada ao novo paradigma de desenvolvimento, novos enfoques e maneiras de intervenções governamentais são traçados.

Todavia, Mansuri e Rao (2004) afirmam que as iniciativas de base comunitária só conseguirão alcançar o desenvolvimento sustentável a partir de um arranjo institucional propício. Essas especificidades locais, quando impostas a partir de uma determinação legal para acesso a políticas públicas, poderiam implicar construções simbólicas com baixo nível de enraizamento, aparentemente voltadas ao atendimento de diretrizes específicas, mas pouco capazes de emancipar a população local. Por outro lado, mesmo em regiões onde o nível de engajamento cívico é baixo e exista certa incapacidade ou desinteresse da população local em responder à indução desse novo contexto de coprodução das políticas e programas governamentais, aliado a contextos clientelistas, a existência de algumas ações, ainda que impostas, poderia ser válida. Essas ações fariam com que a sociedade civil, a partir do convívio e da experiência vivida, transcendesse o conhecimento adquirido (trabalho em grupo, confiança, engajamento) para outros espaços institucionais da vida comunitária (TENDLER, 1998; WAMPLER, 2012; MOHAMMED, 2013).

O novo contexto de desenvolvimento local apega-se, portanto, ao ideário de promoção das condições favoráveis à expansão das características necessárias à promoção desse engajamento co- 
munitário. Esse fato estaria diretamente correlacionado ao incentivo da ação coletiva; à promoção de confiança entre os membros da comunidade e entre eles e o governo; à criação de redes; à participação comunitária; e à cultura cívica. Todas essas características são passíveis de ser agrupado em um único conceito, o de capital social (ALESINA; GIULIANO, 2011; VARELA; MATSUMOTO, 2012).

\section{DIMENSÕES DO CAPITAL SOCIAL NO CONTEXTO DAS POLÍTICAS PÚBLICAS}

O conceito de capital social, segundo Sachs e Lages (2001), acompanha a mudança ideológica do desenvolvimento e foi sendo progressivamente colocado lado a lado com termos como "capital humano", "capital físico" e "capital natural". No entanto, sua utilização tem sido empregada para descrever uma grande infinidade de contextualizações que perpassam a organização informal, a confiança, a cultura, o apoio social, a troca social, os recursos sociais, os contratos relacionais de imersão, as redes sociais e as redes interfirmas.

Para evitar incongruências analíticas, no presente trabalho, utilizou-se como enfoque a definição proposta por Sholz (2003), que distingue por meio de diferentes bases epistemológicas quatro vertentes paradigmáticas do conceito de capital social (Quadro 1). Tal distinção se apega ao enfoque dado por aqueles autores classificados como seminais no âmbito de utilização do conceito e tem sido utilizada em diversos trabalhos acadêmicos, como em Misoczky (2009), Zwich et al. (2010) e Yeary et al. (2012).

Quadro 1 - Paradigmas do capital social

\begin{tabular}{|c|c|c|}
\hline & \multicolumn{2}{|c|}{ Nível de observação } \\
\hline & Micro & Macro \\
\hline $\begin{array}{c}\text { Coesão So- } \\
\text { cial }\end{array}$ & $\begin{array}{l}\text { Utilitarismo racional } \\
\text { Autor: Coleman } \\
\text { Pergunta central: status obtido } \\
\text { Ênfase: ação com propósito } \\
\text { Origem teorizada: escolha } \\
\text { Conceitos-chave: fechamento, multiplexidade } \\
\text { Unidade de obser.: individual }\end{array}$ & $\begin{array}{l}\text { Funcionalismo estrutural } \\
\text { Autor: Putnam, Fukuyama, Evans } \\
\text { Pergunta central: cooperação } \\
\text { Ênfase: aspectos cognitivos } \\
\text { Origem teorizada: normas } \\
\text { Conceitos-chave: confiança } \\
\text { Unidade de obser.: sociedades nacionais }\end{array}$ \\
\hline $\begin{array}{l}\text { Desigualda- } \\
\text { des sociais }\end{array}$ & $\begin{array}{l}\text { Sociologia econômica } \\
\text { Autor: Lin, Burt, Portes } \\
\text { Pergunta central: tomada de decisão } \\
\text { Ênfase: aspectos estruturais } \\
\text { Origem teorizada: redes } \\
\text { Conceitos-chave: troca social } \\
\text { Unidade de obser.: redes sociais }\end{array}$ & $\begin{array}{l}\text { Perspectiva do conflito } \\
\text { Autor: Bourdieu } \\
\text { Pergunta central: reprodução social } \\
\text { Ênfase: poder simbólico } \\
\text { Origem teorizada: encobertamento } \\
\text { Conceitos-chave: habitus e campo } \\
\text { Unidade de obser.: frações de classe social }\end{array}$ \\
\hline
\end{tabular}

Fonte: adaptado de Scholz, 2003.

Os quatro Quadrantes delimitadores estariam compreendidos sob dois contextos de segmentação. $O$ primeiro deles distinguirá o nível de análise: os autores que defendem o capital social como realidade social advinda de critérios individualistas ou da interação de grupos pequenos seria o nível de análise micro. No nível de análise macro estariam os autores que creditam os fenômenos sociais aos resultados dos aspectos macrossociais, portanto eles são passíveis de influenciar comunidades e/ou nações inteiras.

O segundo contexto de segmentação epistemológica se depreenderia da dualidade coesão social/reprodução das desigualdades sociais. No que se refere à coesão social, os autores enfatizam que o capital social atuaria como a unificação de forças, o que acarretaria benefícios generalizados (SCHOLZ, 2003). 
POLÍTICAS PÚBLICAS DE DESENVOLVIMENTO LOCAL E ADENSAMENTO DE CAPITAL SOCIAL: ANÁLISE DO PROGRAMA DE AQUISIÇÃO DE ALIMENTOS (PAA) EM QUATRO MUNICÍPIOS DE MINAS GERAIS

Já com relação ao enfoque denominado de reprodução das desigualdades sociais, o conceito seria empregado para manter privilégios de grupos homogêneos, como grupos de empresários, partidos políticos e segmentos trabalhistas.

A perspectiva compreendida no paradigma denominado de Utilitarismo Racional é analisada pela visão teorizada por James Coleman, cujas bases têm forte enraizamento na Teoria da Escolha Racional. Dessa forma, compreendendo uma dimensão da estrutura social, o capital social se transforma em um recurso que facilita aos atores atingirem seus objetivos, independentemente dos valores que orientem esses objetivos, sejam estes valores moralmente bons ou maus (SERAFIM; ANDION, 2010).

Sob a vertente da Sociologia Econômica, o capital social, evidenciado principalmente pelas abordagens de Ronald Burt, Alejandro Portes, Nan Lin, é pautado pela Teoria das Redes Sociais. A Sociologia Econômica e a Teoria das Redes Sociais se sobrepõem na medida em que tentam explicar os fenômenos econômicos a partir de referências sociais. Além disso, também levam em consideração a localização e o nível de imersão das redes que envolvem o indivíduo para formação de seus interesses e suas decisões (MARTES, 2009).

O paradigma da Perspectiva do Conflito tem por prerrogativas a defesa do capital social para manutenção das desigualdades sociais, tendo os pressupostos de Pierre Bourdieu como pontos centrais. Na concepção de Scholz (2003), a aquisição de status por meio da mobilização de recursos sociais, como confiança e solidariedade, é que causa maior nível de capital social, compreendido apenas a grupos homogêneos interessados em manter seus privilégios.

Por fim, o Funcionalismo Estrutural estaria atrelado aos benefícios societais do capital social, como um maior senso crítico da população no tocante à política local e aos maiores níveis de voluntariado. Portanto, advoga-se que o valor evidenciado na confiança, as informações e as normas são resultantes de uma organização social favorável (SHOLZ, 2003). Daí decorre que nessa vertente paradigmática há uma estreita relação entre capital social e a sociedade civil, notavelmente a partir de critérios advindos de organizações horizontais e do engajamento cívico generalizado (TITECA; VERVISCH, 2008).

O paradigma do Funcionalismo Estrutural compreenderia aqueles autores que defendem o capital social como os aspectos normativos que proporcionam a confiança e a cooperação em níveis macroambientais, como sociedades nacionais, cidades e bairros, sendo, portanto, aquela vertente teórica mais propicia à análise das políticas públicas. Nesse contexto estariam os trabalhos de Robert Putnam, Peter Evans e Francis Fukuyama.

Apesar de Sholz (2003) não fazer referência a Peter Evans, diversos autores classificam seus trabalhos no âmbito do Funcionalismo Estrutural. Isso pode ser observado em Szreter e Woolcock (2004), Ortolani (2005) e Nalle Jr. (2006). Esses autores colocam lado a lado as conceituações de Putnam $(1993,2006)$, Fukuyama $(1995,2002)$ e Evans (1996).

Com a inserção da visão de Peter Evans (1996) no escopo do paradigma do Funcionalismo Estrutural, surge a dualidade no cerne de seu ponto focal, qual seja, a dicotomização entre estrutura e cultura. Figueiras (2001) revela que existe o debate e a tendência entre os autores seminais acerca da utilização do conceito no âmbito das políticas públicas, e a grande questão que divide concepções diz respeito ao dilema cultura/estrutura. $O$ embate epistemológico é "decidir, se o capital social se determina pelos valores, normas e costumes que são internalizados desde a juventude [...], ou se ele nasce de interações sociais [...]" (idem, p. 4).

Putnam (2006), principalmente, demonstra-se que a comunidade cívica é resultado do alto nível de capital social institucionalizado ao longo do tempo e, portanto, inerente à cultura local. Já pela concepção de Evans (1996), o capital social é fruto de uma configuração institucio- 
nal propícia, alegando-se, inclusive, que o capital social encontra-se em latência, devendo ser despertado por meio de uma ação do Estado.

Diversos estudos têm demonstrado que a perspectiva proposta por Peter Evans tem sido aquela adotada pelos policy makers (TENDLER, 1998; DURSTON, 2001; GRINDLE, 2004). Sob esta perspectiva, o Estado, por meio das políticas públicas, seria um importante agente indutor de maiores níveis de capital social.

No entanto, a partir dessa perspectiva, não basta ao governo promover as iniciativas. Como portador direto da capacidade de interferir no capital social, deve também contribuir com sua sustentação por meio da contínua mobilização, pois os resultados e o grau em que os problemas locais serão resolvidos irão depender da capacidade de articulação da esfera pública com a esfera social (LOWNDES; PRATCHETT, 2008; FERRARINI, 2012).

\section{O PAA ENQUANTO POLÍTICA PÚBLICA DE DESENVOL- VIMENTO LOCAL}

O Programa de Aquisição de Alimentos (PAA) foi criado em 2003, a partir da articulação do Conselho Nacional de Segurança Alimentar e Nutricional (CONSEA) com o Governo Federal, cuja normatização legal foi dada pela Lei n. 10.696; posteriormente ele veio a ser regulamentado pelo Decreto n. 4.772, de 2 de julho de 2003.

Em relação aos seus objetivos, o PAA, a partir dos agentes executores, adquire produtos oriundos da agricultura familiar destinando-os, por meio de doação, a segmentos populacionais em risco de insegurança alimentar. Diante de suas diversas modalidades, Corrêa (2008) ressalta o fato de que a tendência do programa é favorecer aquelas linhas que só podem ser acessadas mediante organizações coletivas, com o intuito de contribuir para a organização, a autonomia e o aprendizado dos agricultores.

Quanto à sua gestão e execução é possível perceber, pela Figura 1, que o programa, na modalidade, aqui analisada, que perpassa a formação de empreendimentos coletivos da agricultura familiar, engloba atores governamentais de distintas esferas, níveis e autarquias da administração pública e da sociedade civil organizada. 
Figura 1 - Níveis governamentais dos atores diretamente envolvidos na execução do PAA

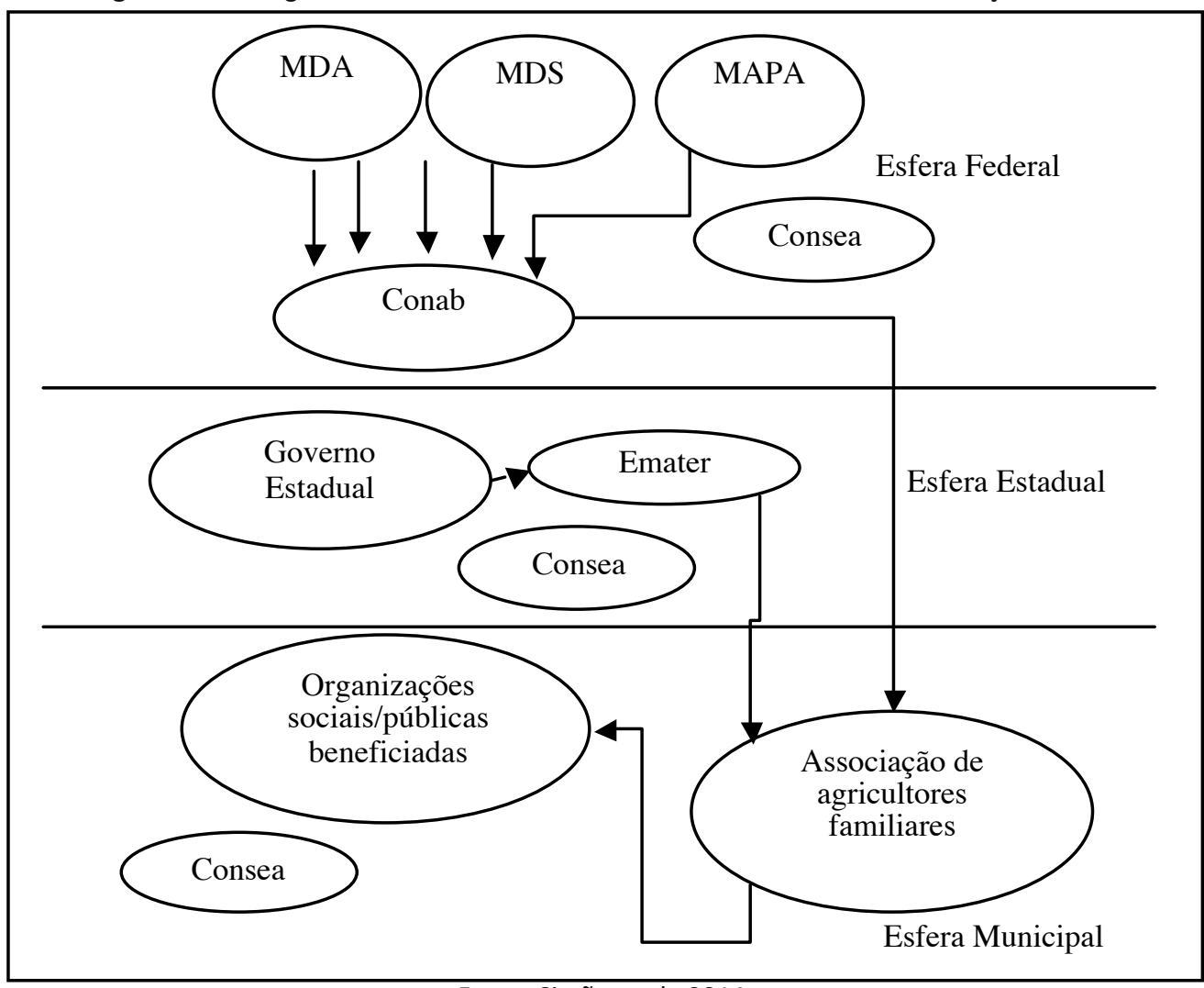

Fonte: Simão et al., 2014

Na esfera federal de governo, a Companhia Nacional de Abastecimento (CONAB), autarquia do Ministério da Agricultura, Pecuária e Abastecimento (MAPA), unidade executora do PAA adquire alimentos dos produtores rurais familiares organizados em empreendimentos coletivos sem a existência do procedimento licitatório, e os repassa aos beneficiários. Os recursos públicos destinados à CONAB advêm, por sua vez, de rubricas orçamentárias do Ministério do Desenvolvimento Social e Combate à Fome (MDS) e do Ministério do Desenvolvimento Agrário (MDA).

$\mathrm{Na}$ instância estadual, especificamente no contexto de Minas Gerais, a Empresa de Assistência Técnica e Extensão Rural do Estado de Minas Gerais (EMATER) é a responsável por chancelar a condição de agricultor familiar dos produtores rurais, bem como de suas organizações coletivas. Dessa forma, a EMATER é a responsável pela emissão da Declaração de Aptidão ao PRONAF (DAP), principal pré-requisito de acesso ao PAA.

Outra organização que figura no escopo de atuação do PAA é o Conselho de Segurança Alimentar (CONSEA) que se encontra presente em todos os níveis governamentais. O CONSEA tem por atribuição ser a instância auxiliar de controle social das ações propostas pelos diversos atores envolvidos na execução do programa. Assim, é esse órgão que ratifica o documento de propositura à participação no programa, valida os participantes (agricultores e entidades beneficiárias), acompanha a execução, supervisiona a gestão do programa e auxilia na definição dos alimentos passíveis de doação. 


\section{METODOLOGIA}

A natureza da pesquisa teve por base uma abordagem predominantemente qualitativa e descritiva. Optou-se pela análise do PAA em sua linha de operacionalização Compra com Doação Simultânea realizada pela $\operatorname{CONAB}^{6}$ em quatro municípios do estado de Minas Gerais.

Ressalta-se que a escolha da linha de operacionalização analisada deu-se também em função da modalidade de Doação Simultânea operacionalizada pela CONAB ser aquela que no ano de 2012 foi a que mais recebeu recursos públicos do programa (BRASIL, 2011).

Tabela 1 - Participação de Minas Gerais nos repasses do PAA por modalidades em 2011

\begin{tabular}{ccc}
\hline Modalidade & total de recursos pagos - Brasil (R\$) & $\begin{array}{c}\text { Recursos pagos em Minas Gerais } \\
\text { (R\$) }\end{array}$ \\
\hline Doação Simultânea - CONAB & $418.838 .027,81$ & $42.026 .703,72$ \\
\hline Doação Simultânea - Estadual & $49.006 .777,19$ & - \\
\hline Doação Simultânea - Municipal & $41.532 .321,72$ & $8.396 .739,37$ \\
\hline PAA Leite & $157.948 .363,44$ & $32.602 .262,00$ \\
\hline
\end{tabular}

Fonte: Brasil, 2011.

No contexto de atuação das ações do PAA, Minas Gerais destacou-se, em 2013, como uma das principais unidades federativas quanto à participação nos volumes dos recursos pagos (Tabela 1). Além disso, segundo dados do Censo Agropecuário (IBGE, 2006), Minas Gerais possuía cerca de $80 \%$ dos mais de 500 mil estabelecimentos rurais classificados na classe de agricultores familiares.

No entanto, quando se compara a localização daqueles municípios que apresentam as características prioritárias de demanda do programa com os municípios que obtiveram propostas aprovadas, nota-se que a Zona da Mata foi, em 2011, foi aquela com menor taxa porcentual de cobertura (SIMÃO et al., 2014). Duas situações poderiam ser inferidas a partir desse contexto, a primeira, diz respeito ao desconhecimento dos municípios em relação ao programa, a segunda, estaria relacionada ao fato de os municípios terem comercializado e por algum motivo não terem renovado novas propostas de participação.

Assim, o recorte observacional dos municípios pesquisados deu-se em função de dois aspectos: o geográfico e o socioeconômico. Como unidades de análise, foram escolhidas as microrregiões de Viçosa e Ponte Nova, pertencentes à mesorregião da Zona da Mata do estado de Minas Gerais. Dentre os municípios pertencentes às duas microrregiões foram previamente selecionados aqueles que operacionalizaram com o PAA no período de 2010 a 2012. Diante dessas características iniciais foram contabilizados 15 municípios.

A partir dessa pré-seleção, foram considerados no conjunto desses 15 municípios os seguintes critérios para a definição final (refinamento) das localidades a serem pesquisadas: o porcentual de população residente em meio rural; os níveis de população rural em linha de extrema pobreza; e a situação de desenvolvimento local do município, considerando o IDH do ano 2000. Feito o recorte, com base nos indicadores, foram objetos de estudo final 4 municípios, quais sejam: Amparo do Serra, Jequeri, Guaraciaba e Alto Rio Doce. Esses municípios foram os que apresentaram, no conjunto de localidades pré-selecionadas, IDH abaixo da média do estado, e, por outro lado, percentual de população rural e população rural extremamente pobre acima das médias de Minas Gerais.

Realizada a seleção das localidades a serem pesquisadas, optou-se pela realização de entrevistas, enquanto método para a coleta dos dados primários da pesquisa. As entrevistas, realizadas a partir de roteiros pré-determinados para cada um dos segmentos de atores pesqui-

6 A presente modalidade só pode ser acessada mediante a organização dos produtores rurais em empreendimentos coletivos. 
sados, foram conduzidas no período de 3 de julho a 10 de outubro de 2013.

Os roteiros utilizados nas entrevistas a cada um dos segmentos de atores definidos foram compostos por categorias operacionais passíveis de oferecerem uma análise acerca do conceito de capital social local e os possíveis efeitos advindos com a implementação e operacionalização do PAA. Em relação à constituição dessas categorias operacionais optou-se por uma adaptação dos quatro indicadores sugeridos por Zudewich e Norris (2005) (Quadro 2).

Quadro 2 - Categorias e enfoques utilizados para a análise do capital social

\begin{tabular}{cl}
\hline Categoria & \multicolumn{1}{c}{ Enfoques de Análise } \\
\hline & $\begin{array}{l}\text { Quais tipos, recursos e suportes governamentais os envolvidos obtêm } \\
\text { para participação no programa; } \\
\text { Deficiências de comunicação governamental em torno da implementa- } \\
\text { ção e operacionalização do programa; }\end{array}$ \\
$\begin{array}{cl}\text { Suporte Governamental e Re- } \\
\text { des Sociais envolvidas no PAA }\end{array}$ & $\begin{array}{l}\text { Capacidade do grupo para resolver uma ou mais questões específicas; } \\
\text { Principais fatores que impedem/favorecem a mobilização da rede en- } \\
\text { volvida na operacionalização do PAA; } \\
\text { Como a rede de atores envolvidos cria/dificulta acesso para outros re- } \\
\text { cursos ou novas oportunidades (limitações e potencial). }\end{array}$ \\
\hline Participação no PAA & $\begin{array}{l}\text { Envolvimento ativo dos atores em prol do programa; } \\
\text { Nível de envolvimento no empreendimento coletivo. }\end{array}$ \\
\hline Confiança entre os atores lo- & $\begin{array}{l}\text { Nível de confiança, solidariedade e identificação entre os envolvidos na } \\
\text { rede. }\end{array}$ \\
\hline Participação Cívica & Engajamento na ação cívica (questões políticas locais/nacionais). \\
\hline da comunidade local &
\end{tabular}

Assim, a técnica utilizada para a análise das informações coletadas na pesquisa de campo, por meio das entrevistas, foi a da análise de conteúdo com indicadores definidos à priori.

Destaca-se ainda, que todas as entrevistas foram gravadas, com o consentimento prévio dos sujeitos de pesquisa, e posteriormente transcritas. O número total de entrevistados, bem como sua categorização em relação aos atores envolvidos na operacionalização do PAA estão evidenciadas na Tabela 1.

Tabela 2 - Segmentação e número de entrevistas realizadas

\begin{tabular}{cccccc}
\hline & Alto Rio Doce & Amparo do Serra & Guaraciaba & Jequeri & Belo Horizonte \\
\hline Produtores & 3 & 5 & 7 & 4 & \\
\hline Entidades Beneficiárias & 4 & 3 & 5 & 5 & \\
\hline $\begin{array}{c}\text { Técnicos de Extensão rural } \\
\text { (EMATER) }\end{array}$ & 1 & 1 & 1 & 1 & \\
\hline Unidade Executora (CONAB) & - & - & - & - & 1 \\
\hline Total & $\mathbf{8}$ & $\mathbf{9}$ & $\mathbf{1 3}$ & $\mathbf{1 0}$ & $\mathbf{1}$ \\
\hline
\end{tabular}

Fonte: dados da pesquisa.

Por fim, é preciso ressaltar que foi realizada a triangulação de informações entre os respondentes. Dessa forma como o primeiro entrevistado, na maioria das vezes, foi o extensionista rural local, o número total de produtores rurais e de representantes das organizações sociais participantes foi delimitado quando as informações eram corroboradas entre si. 


\section{RESULTADOS}

\subsection{Capital Social e o PAA nos municípios pesquisados}

\subsubsection{Suporte Governamental e redes socais envolvidas na operacionalização do PAA}

Nesta primeira categoria foi analisado o suporte governamental 7 recebido pelos diversos atores (agricultores, extensionistas e entidades beneficiárias) envolvidos na efetivação e operacionalização local do PAA, bem como as redes sociais existentes. Neste trabalho, entendeu-se por redes sociais as relações (ligações) existentes entre os diversos agentes localmente envolvidos na execução do programa.

Em todos os municípios pesquisados, nenhum dos beneficiários entrevistados (agricultores e entidades receptoras dos alimentos) acenou positivamente com relação a qualquer tipo de contato prévio da CONAB ou de qualquer um dos órgãos gestores do PAA, seja para divulgação, orientação e/ou treinamento acerca do funcionamento do programa. A única referência à CONAB notada nos depoimentos foi no município de Amparo do Serra, onde o representante de uma das entidades beneficiadas com a doação de alimentos mencionou a visita de um fiscal da entidade.

Além disso, o processo de implementação dos projetos do PAA não foi realizado de forma participativa, causando desconhecimento junto aos próprios atores locais envolvidos acerca do programa. Foi recorrente nas entrevistas com os produtores rurais e as entidades beneficiárias o desconhecimento do nome do programa, devendo ser ressaltado que em alguns casos eles só se recordam do chamado "Programa da CONAB", ou mesmo ligam o programa à própria EMATER. Nos casos em que o programa já não estava mais em vigência, não houve qualquer explicação para as entidades beneficiárias com a doação dos alimentos no tocante aos motivos de sua finalização.

A deficiência de informação relativa ao PAA ficou evidente não somente nas questões referentes ao seu funcionamento, mas ao processo de seleção das propostas enviadas, aos critérios de seleção dos agricultores, à prestação de contas e aos prazos necessários aos pagamentos dos alimentos doados. Com relação a esse fato, a unidade executora em nível estadual (Superintendência Regional da CONAB) admite a ausência de meios de orientação/treinamento em nível local.

Não[se existe um canal direto de comunicação]... que seja uma coisa estipulada de tempos em tempos que a gente realiza... Seminários... Isso não. A gente conta com a EMATER, porque a EMATER é uma das nossas parceiras. Então a EMATER realiza esses esclarecimentos pra... pra...passar esclarecimento para os produtores (Representante da Superintendência Regional da CONAB).

A falta de informação se dá de forma mais notável junto aos agricultores, uma vez que eles não são informados de questões relativas à forma utilizada no cálculo dos valores pagos pela CONAB aos alimentos doados, do tempo necessário à apreciação das propostas de participação e da realização dos pagamentos. Como o processo de prestação de contas é alterado constantemente, as informações só são assimiladas à medida que os projetos são retornados pela unidade executora, por não atenderem aos padrões esperados. Ressaltando o contrassenso evidenciado, Faria (2005) afirma que atualmente os novos processos de execução das intervenções governamentais estão focados muito mais em contornar os problemas percebidos junto ao público beneficiário, do que aquelas voltadas apenas a facilitar o trabalho de decisores e gestores.

Na Figura 2 estão os principais problemas apontados pelos atores locais no tocante ao PAA. Pode-se perceber que grande parte deles está diretamente ligada ao processo deficitário de comunicação entre governo e beneficiários.

7 Por suporte governamental entenda-se o apoio dado pelo governo aos atores locais envolvidos com a operacionalização do PAA. 
Figura 2 - Níveis de recorrência dos problemas apontados pelos atores locais em relação à operacionalização do PAA

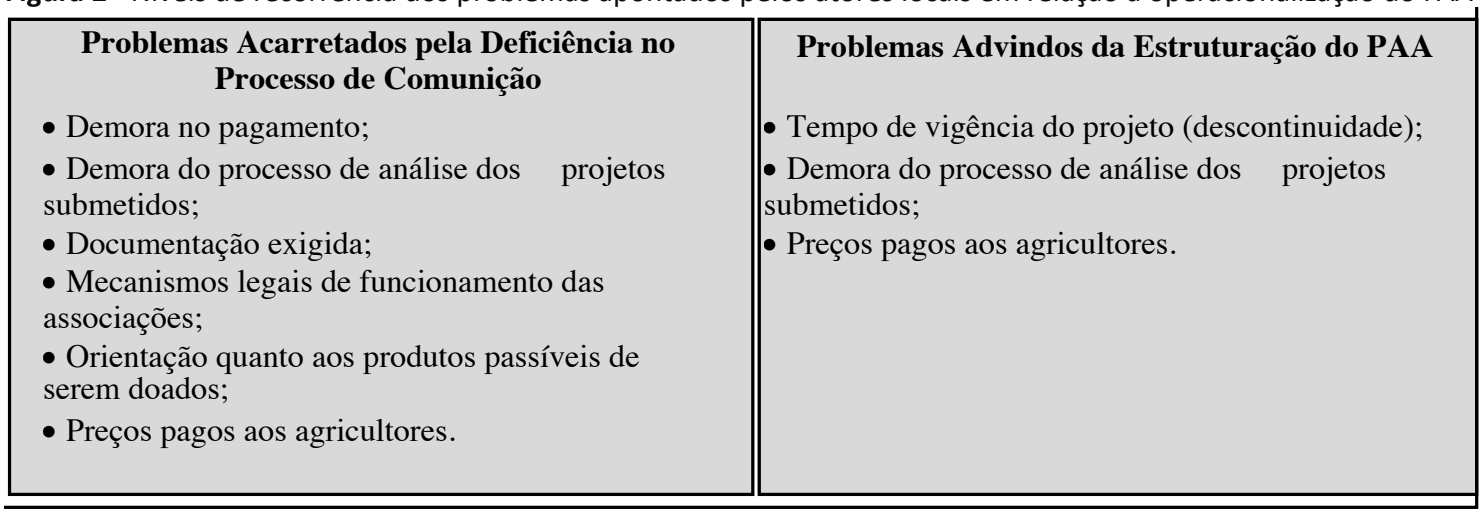

Fonte: dados da pesquisa.

A inexistência de informações repassadas aos atores locais com relação ao modo de elaboração das propostas de participação e da prestação de contas, aliada a mudanças constantes no processo burocrático de prestação de contas e à implementação do PAA, é a principal causa apontada pela desistência e desinteresse do programa.

Só que tem que quando chegou na parte de aprovação do projeto, aí o negócio começou a complicar [...]. Demorou mais de seis meses, agarrado toda vida o projeto [...]. Esse PAA é engraçado, eu acho que é um programa bom [...]. Mas tem que melhorar, tem que ser reestruturado, tem que haver uma outra saída, porque do jeito que tá acontecendo, não tá tendo aceitação por parte dos agricultores não [...] (Técnico de extensão rural - Alto Rio Doce). [...] em nosso município foi enviado um projeto no ano de 2010 e até hoje tá em análise esperando recurso e até hoje nada (Técnico de extensão rural - Jequeri).

Por esse contexto, em que as informações são incipientes, os técnicos de extensão rural da EMATER acabaram por assumir o papel de agente central, atuando na articulação de todas as etapas locais do PAA. Esse cenário ativo de atuação das organizações de extensão rural, no entanto, não é contemplado na concepção original do programa, nem mesmo em sua regulamentação jurídica.

Da forma como tomam a frente na iniciativa de execução local do PAA, os extensionistas acabam por contribuir involuntariamente para a acentuação nas deficiências de informação do público-alvo (agricultores e entidades beneficiadas) em relação aos objetivos e à própria existência do programa, o que evidencia que eles passam a tutorar os beneficiários em todos os trâmites necessários.

Constatou-se que um dos grandes gargalos locais do PAA é a entrega dos produtos. A maioria dos agricultores tem de se deslocar da zona rural dos municípios para realizar a entrega por conta própria. Essa situação cria alguns problemas, principalmente quanto às dificuldades de transporte para aqueles produtores que não dispõem de veículos próprios. Percebeu-se também que o armazenamento e o transporte são feitos de forma inadequada, em alguns casos, como é o caso de transportes em motocicletas e em ônibus escolares. Por outro lado, esse fato é bastante minimizado quando a associação possui veículo próprio, o que foi somente constatado na associação de Alto Rio Doce.

O apoio do poder público municipal foi mencionado nos municípios de Jequeri e Guaraciaba, de duas formas distintas. Em Jequeri há apenas a distribuição dos alimentos para as entidades beneficiárias, logo os produtores rurais têm de se deslocar da zona rural até o ponto de coleta e distribuição, geralmente a sede da EMATER.

Nesse caso, o problema da logística da propriedade rural até o centro de distribuição continua a existir. Já em Guaraciaba existe a disponibilização de um motorista e um veículo do município 
para a coleta, a pesagem e o transporte até o local do ponto de distribuição de todas as associações do município. Nesse ponto de distribuição, que conta também com uma funcionária cedida pela prefeitura municipal, são realizadas a separação e a destinação dos alimentos para as entidades beneficiárias.

Com exceção do município de Jequeri e do município de Guaraciaba, notou-se a incipiência do apoio do poder público local nas questões inerentes ao PAA em Amparo do Serra e Alto Rio Doce.

\subsubsection{O grau de exclusão de produtores rurais não participantes}

O motivo mais citado para a não participação da maioria dos produtores rurais no PAA, segundo os entrevistados, diz respeito ao descrédito local do programa. Essa situação ainda se divide em dois cenários, relacionados ao receito de as ações do programa não darem certo e ao desinteresse. $O$ desinteresse difere do descrédito em virtude da incompatibilidade da produção agropecuária local com aqueles produtos que podem ser entregues ou adquiridos pelo programa.

Outro aspecto que gera desinteresse está relacionado à localização geográfica das propriedades rurais, uma vez que grande parte delas se localiza em regiões distantes dos locais de entrega, situação esta mencionada em todos os municípios pesquisados.

[...] a CONAB agora, esse projeto nosso aí ainda é $\mathrm{R} \$ 3.500$, então o que acontece, o produtor que trabalha no PAA é aquele pequeno mesmo, e o pequeno ele tem dificuldade, a pessoa tem lá, um exemplo, 50 quilos de um produto pra trazer, se ele tiver um pouco distante, que não dá pra ele trazer de cavalo, alguma coisa assim, ele não tem condições de pagar o frete, se pagar o frete fica tudo (Técnico de extensão rural - Amparo do Serra).

A falta de esclarecimento quanto aos benefícios e ao funcionamento do PAA em nível local também foi caracterizada como uma questão limitante à participação de outros agricultores. Essa deficiência de informação foi mencionada nos municípios de Guaraciaba e Jequeri.

Por fim, as questões relativas ao modo de operacionalização do programa também foram citadas como um fator impeditivo à agregação de novos produtores beneficiados em nível local. Essas questões estariam relacionadas à dificuldade institucional-legal de criação dos empreendimentos coletivos e ao próprio modo de funcionamento desses empreendimentos, conforme se percebe no depoimento abaixo.

Muitos não entraram porque têm que pagar uma mensalidadezinha, eu acho que é isso, né?! É muita gente preguiçosa [...] a minha sobrinha mesmo, foi lá e fez a carta [...] e passou a carta pra mim, e eu tô acabando de entregar ela [...] (Agricultor 6 - Guaraciaba).

Como não existe orientação prévia acerca do funcionamento das organizações coletivas, nem tradição cultural da existência local desse tipo de organização na grande maioria dos municípios, muitos produtores não possuem conhecimento dos encargos fiscais e contábeis a serem pagos pelos associados. Esta situação gera descontentamento e inibe a participação e/ou criação de outras associações.

Como a densidade da rede dos atores envolvidos na operacionalização local do PAA é baixa, percebeu-se um nível descendente de interesse de participação no programa. Com exceção dos municípios de Guaraciaba e Amparo do Serra, os outros já não possuem mais projetos vigentes e nem mesmo interesse na submissão de novas propostas. Esse fato se deve ao grande número de problemas operacionais do programa, aliado à falta de orientação e ao padrão excessivamente burocrático de sua atuação. Diante desses problemas, os atores locais preferem abandonar o programa, na maioria das vezes pela própria orientação do técnico de extensão rural. 
Mesmo diante desses problemas operacionais, foi possível perceber em Guaraciaba um engajamento maior dos envolvidos na resolução dos problemas locais, o que é atribuído ao fato de muitos agricultores terem apontado a figura do presidente da associação como responsável pela solução de problemas envolvendo o programa, e não somente a figura do técnico de extensão rural, como foi recorrente nos outros municípios pesquisados.

[...] tem um pouco [dificuldade de preenchimento de papeis]. É a associação tem um contador também, né?! Mas o contador não faz as contas, é a presidente mesmo que faz a contabilidade (Agricultor 5 - Guaraciaba).

A existência de uma pessoa, envolvida na organização coletiva, em quem os produtores depositam a confiança também foi apontada por Neiva e Brito (2008) como algo favorável e de grande valia para a perenidade de associações criadas para a operacionalização de políticas públicas.

\subsubsection{Participação no empreendimento coletivo e níveis de ação coletiva entre os agricultores}

No município de Jequeri, constatou-se a influência de um deputado estadual que tinha articulado junto à EMATER a formação da associação e a implementação do PAA no município.

Ah... foi o deputado Joaquim Gomes [...] esse projeto já tinha em várias regiões aqui. Começou primeiro com Ponte Nova, ele que ajudou a gente a formar a associação, mandou o assistente ajudar a gente formar a associação, porque pra gente participar de qualquer coisa precisa da gente tá na associação. E com o primeiro projeto foi acho que através dele (Agricultor 5 - Jequeri).

Em Amparo do Serra o empreendimento coletivo tinha por finalidade o atendimento das demandas interpostas para a operacionalização da política pública. Segundo o técnico de extensão rural local, o sistema institucional-legal que rege o funcionamento de organizações desse tipo (associações e cooperativas) tende a dificultar seu funcionamento. Foi também nítida a percepção dos agricultores locais quanto ao funcionamento da associação estar atrelado apenas à vigência do PAA.

Além disso, ficou claro no depoimento do extensionista ligado à EMATER local que a associação criada a partir de uma demanda normativa não tem perspectivas de funcionamento no município.

O pessoal só faz ali, só une porque é uma obrigação [...]. Agora essa associação formal, forçada que o governo tenta fazer [...] não funciona [...]. Acaba a política pública, que só faz pra aquela função, né?! Na verdade, quando você escuta o pessoal falando da associação, eles falam assim: "vamo montar uma associação pra ver se nós consegue um dinheiro" (Técnico de extensão rural - Amparo do Serra).

Constatou-se em Alto Rio Doce, assim como nos demais municípios, que a orientação aos produtores rurais para se organizarem de forma coletiva, por meio da associação, partiu do técnico da EMATER e de um dos produtores rurais que arcou com parte das despesas de registro do empreendimento. Contudo, o técnico de extensão rural apenas assessora o funcionamento da associação, prestando esclarecimentos e criando o canal de contato entre os diversos atores envolvidos no PAA. Nesse sentido, ele não intervém ativamente nas atividades rotineiras da associação.

Como o extensionista atua de forma mais indireta, a associação mostrou arranjo operacional mais autônomo. Além do veículo, a associação dispõe de estrutura organizacional mais desenvolvida, pois uma das associadas, também fornecedora de alimentos, atua secretariando a organização, articulando e auxiliando os demais associados nas operações da entidade. 
O município de Guaraciaba foi, dentre todos os pesquisados, aquele que apresentou o maior número de projetos, como também o maior número de organizações coletivas. Ao todo foram quatro associações distintas que obtiveram projetos aprovados para a operacionalização do PAA.

Percebeu-se também que dentre as associações com projetos aprovados duas diferiam das outras quanto à independência de funcionamento para outros fins que não àqueles ligados ao atendimento às demandas de políticas públicas, no tocante à participação dos associados e à existência de reuniões frequentes.

Esse nível de independência, segundo os depoimentos, estaria ligado ao fato de existirem lideranças entre os associados que atuariam favorecendo a articulação para a ação coletiva. Essa situação vai de encontro às afirmações de Grootaert et al. (2003), que afirmam que a existência de líderes locais contribuem para a criação de conexões sociais favoráveis a eficácia de programas governamentais de desenvolvimento local.

\subsubsection{Confiança entre a população local}

Com relação à solidariedade presente nas localidades pesquisadas, percebeu-se que na grande maioria dos casos as comunidades são pouco unidas para a resolução de problemas e que também são incipientes os níveis de confiança entre seus membros. Tal cenário, nas palavras de Tomas et al. (2012) acaba por afetar e influenciar o desenvolvimento socioeconômico da região. Esse contexto é revertido apenas nas questões que perpassam o aspecto religioso e os aspectos inerentes a questões de saúde.

No município de Amparo do Serra constatou-se a incipiência de práticas solidárias entre os membros da comunidade local. Em duas das entrevistas realizadas foi externada a questão das divergências político-partidárias como fator impeditivo à união da população local, conforme se percebe nos depoimentos a seguir.

[...] Não tem união, porque infelizmente a política partidária interfere nesse quadro, interfere muito [...]. Existe aquela vaidade pessoal, "Ah! Mas eu represento fulano de tal, eu sou de tal partido", eles associam a minha pessoa e não o meu trabalho (Beneficiário 2-Amparo do Serra).

No município de Alto Rio Doce, segundo o técnico de extensão rural local, há uma tendência descendente no que se refere às práticas de união e solidariedade entre os produtores rurais.

Olha, já existiu muito sabe [mutirões e trocas de dias], antes assim, o grupo trabalhava no mutirão pra plantio, milho que é o produto principal aqui é milho, feijão, né?! Os produtores geralmente fazem, mas mutirão mais assim, às vezes pra limpeza de pasto, esses trem tudo, na produção já não tá tendo mais não [...] (Técnico de extensão rural Alto Rio Doce).

Contrastando as percepções, mesmo diante da incipiência de ações grupais na comunidade rural, há a expectativa dentre aqueles associados de que em situações de necessidade eles poderão contar com o auxílio de seus pares. Essa situação indica que a interação, mesmo que deficitária, gera um sentimento grupal e, consequentemente, maiores níveis de confiança entre seus membros.

Com relação ao município de Jequeri, segundo depoimento do técnico de extensão rural local, há um alto nível de individualismo entre os produtores rurais locais, e mesmo na comunidade de modo geral, que só é superado nos dois enfoques comuns aos outros municípios (religião e doença).

Aqui infelizmente ainda predomina o individualismo [..], há uma desconfiança muito 
grande no outro. Então você trabalha o associativismo, mostrar que ele precisa de participar de uma reunião, que hoje é um que é beneficiário, amanhã pode ser outro [...]. A venda, por exemplo, do leite, que é um produto maior aqui também no nosso município, ainda é muito individual, porque eles ficam às vezes, brigando aí, por causa de 2, 3 centavos no leite [...]. A união do nosso município [...], a gente vê, por exemplo, as festividades religiosas, a comunidade toda participa [...], a gente vê também um trabalho maior da questão de saúde [...] (Técnico de extensão rural - Jequeri).

Por fim, no município de Guaraciaba houve a percepção de que o contexto local vem se alterando ao longo dos últimos anos e constatou-se que cada vez mais a população passa a se articular de maneira coletiva para reivindicar melhores condições de vida. Isso estaria acontecendo predominante de forma especial com os produtores rurais locais.

A cultura nossa ainda é bastante individualista, bastante dificuldade de trabalhar de forma associativa [...]. Mas, se a gente comparar o município a dezesseis anos [atrás] houve uma grande evolução já [...]. O pessoal começa já, assim, a se organizar pra poder reivindicar através das associações (Técnico de extensão rural - Guaraciaba).

Esse nível de engajamento é constatado no depoimento dos agricultores, percebendose ainda um nível de autonomia não presenciado nos outros municípios pesquisados. Evidenciou-se, no caso de Guaraciaba, a presença de certo nível de engajamento entre os agricultores participantes do PAA para solução dos problemas comuns ao grupo, que se mobilizaram para a realização de confraternizações para o pagamento de dívidas acumuladas em uma das associações. Além disso, mesmo na região de localização das outras associações, foi apontando positivamente quando se questionou acerca da união da comunidade local, como pode ser constatado nos depoimentos a seguir.

Ajuda sim [se os demais produtores ajudam no caso d algum problema], porque a gente tem muita amizade. É [se a comunidade é unida]... é muito unida (Agricultor 5 Guaraciaba).

Em questão de mão de obra, [...] um favorece o outro... ajuda o outro sim. Teve caso de vaca atolada aqui, às vezes a gente vai atrás dos vizinhos ajuda [...] (Agricultor 1 Guaraciaba).

Quanto à solidariedade da comunidade de Guaraciaba para com as ações empreendidas pelas diversas entidades sociais, percebeu-se nas entrevistas realizadas com seus representantes que a comunidade é minimamente mais mobilizada que a dos demais municípios pesquisados.

Olha, a gente tem ajuda sim... pequenas ajudas, né?! Gente de muita boa vontade, em questão de doação a gente recebe muito pouco, doação de alimentos... mas recebe [...] tem pessoas sim [...] (Beneficiário 2-Guaraciaba).

Festas, reuniões, convites... eles tão sempre com a gente. Que a escola, ela promove palestra mensalmente aos pais [...]. E nós temos uma presença muito boa. Uma aceitação muito boa das famílias e da comunidade (Beneficiário 4-Guaraciaba).

De todos os municípios pesquisados, Guaraciaba foi o que apresentou quadro institucional mais favorável às relações de confiança e solidariedade entre os entrevistados. 


\subsubsection{Participação Cívica}

No município de Amparo do Serra percebeu-se uma disputa político-partidária muito expressiva. Ademais, constatou-se nos depoimentos dos agricultores entrevistados no município que o processo eleitoral se resume apenas ao ato de votar, cumprindo, portanto, um compromisso normativo.

De maneira semelhante, os entrevistados do município de Jequeri também preferem, no âmbito eleitoral, cumprir apenas suas obrigações legais, e não se envolver nas questões de militância e engajamento político-partidário.

Não [participa das eleições]. Não sobra tempo pra ir em Jequeri não, só no torneio leiteiro mais que a gente vai lá (Agricultor 3 - Jequeri).

Os produtores rurais do município de Alto do Rio Doce demonstram mais engajamento que os das cidades de Amparo do Serra e Jequeri. Esse cenário, inclusive, pode ser comprovado pelo fato de que antes da associação possuir veículo próprio os alimentos eram coletados pelos veículos da prefeitura local, o que foi implementado por reivindicação dos agricultores.

No município de Guaraciaba notou-se uma interação maior entre os agricultores e o poder público municipal. Tal interação, no âmbito político ocasionou a cessão de funcionária (secretária) e local (salão) para distribuição e contabilização dos alimentos comercializados junto ao PAA, que foram implementados a partir da mobilização dos produtores rurais. Essa interação também se refletiu na questão da participação do processo político local, inclusive um dos produtores rurais entrevistados fez questão de afirmar que já foi candidato a vereador.

\section{CONSIDERAÇÕES FINAIS}

Em relação à estruturação local do PAA, nos municípios pesquisados, constatou-se a existência de vieses operacionais que tornam a implementação e a operacionalização do programa deficitária, o que compromete os incentivos ao aumento dos níveis de capital social, a partir da intervenção governamental. Tais vieses estão relacionados ao funcionamento limitado das associações participantes, à baixa interação grupal entre os produtores, assimetria de comunicação governamental com os participantes, falta de apoio do poder público municipal e falta de estrutura e atuação tutorial da extensão rural pública local.

Observou-se, a partir desse contexto, que a implementação e a operacionalização do PAA ocorrem na base da tentativa e erro. Dessa forma, à medida que ocorre a rejeição das propostas ou das prestações de conta, os extensionistas rurais entram em contato com a unidade executora (SUREG-CONAB) e, a partir daí, buscam orientação para solução dos problemas encontrados.

Esse cenário é minimamente alterado no município de Guaraciaba, o que pode ser explicado por dois fatores, que não foram constatados em outros municípios: a existência de algumas associações cujo funcionamento é autônomo e independente da atuação dos extensionistas rurais, atribuído principalmente à existência de lideranças locais; e também o expressivo apoio do poder público municipal.

Outro fator percebido é que a forma de atuação dos extensionistas é ainda marcada por um enfoque tutorial que acaba por dificultar o papel mais ativo dos atores locais envolvidos. Assim, ao serem criados empreendimentos coletivos cujo "funcionamento" seja meramente instrumental, as condições necessárias ao adensamento do capital social local, como solidariedade, identidade e confiança, simplesmente não ocorrem ou tornam-se muito superficiais. 
POLÍTICAS PÚBLICAS DE DESENVOLVIMENTO LOCAL E ADENSAMENTO DE CAPITAL SOCIAL: ANÁLISE DO PROGRAMA DE AQUISIÇÃO DE ALIMENTOS (PAA) EM QUATRO MUNICÍPIOS DE MINAS GERAIS

A análise do PAA nos municípios pesquisados, a partir do enfoque metodológico proposto neste trabalho, deixa também evidente que a descentralização das políticas públicas sem a articulação dos distintos atores envolvidos, notavelmente aqueles mais próximos aos beneficiários, torna o processo pouco eficaz. Destaca-se, neste contexto, inclusive, que a indução de níveis mais elevados de capital social fica comprometida. Esse fato vai ao encontro do que já ressaltavam Vasconcelos e Vasconcelos Sobrinho (2011), ao externarem que o pouco entendimento dos atores locais a respeito da gestão do processo de coprodução desgasta antecipadamente o processo de adensamento do capital social.

Ao contrário de pesquisas empíricas realizadas por Tendler (1998), Durston (1999) e Grindle (2004), em que se evidencia o fato de que capital social pode ser criado mesmo naquelas localidades onde a tradição sociocultural não evidencie altos níveis de ação coletiva, coesão social e engajamento cívico, os resultados alcançados nesta pesquisa inferem a necessidade de uma ressalva. Os apontamentos externados por Putnam (2006), cuja perspectiva culturalista é predominante, são passiveis de serem percebidos. O fato de o programa ter sido implementado numa região de baixo capital social pode ser um dos fatores, aliado às suas deficiências operacionais, que contribuíram para a não perenidade de sua vigência em determinados municípios.

Por fim, é preciso ressaltar algumas limitações da presente pesquisa. Destaca-se o fato de o estudo ter sido conduzido em alguns municípios onde o PAA não obteve continuidade, o que pode tendenciar para a probabilidade da evidenciação de insatisfação entre os atores envolvidos, mesmo essas localidades tendo sido selecionadas por critérios técnico-metodológicos. Tais fatos, não permitem, dessa forma, a extrapolação das inferências para outras localidades geográficas de execução do programa.

Todavia, os resultados percebidos de maneira geral nos quatro municípios pesquisados apontam para a necessidade de alguns aperfeiçoamentos, no âmbito da implementação e operacionalização do PAA, destacando-se a capacidade de capilaridade das informações em torno da intervenção, a coparticipação dos níveis governamentais mais próximos aos beneficiários, a meIhoria da infraestrutura física e humana dos atores governamentais envolvidos e a proatividade dos potenciais beneficiários.

\section{REFERÊNCIAS}

ALESINA, A.; GIULIANO, P.. Family ties and political participation. Journal of the European Economic Association, v. 9, n. 5, p. 817-839, abr., 2011.

APPENDINI, K., NUIJTEN, M. El papel de las instituciones los contextos locales. Revista de Ia CEPAL, n.76, p.71-88, abr., 2002.

BRASIL. Ministério do Desenvolvimento Social e Combate à Fome. PAA Data. 2011. Disponível em: [http://aplicacoes.mds.gov.br/ sagi/paa/2011/visi_paa_geral/pg_principal. php?url=geral_est]. [20/08/2014].

CORRÊA, F. C. M. Programa de Aquisição de
Alimentos (PAA): Uma comparação entre dois estados do Brasil. Brasília/DF. Dissertação (Mestrado) - Universidade de Brasília, Curso de Pós-Graduação em Agronegócios, 2008.

DURSTON, J. Capital social: parte del problema, parte de la solución - Su papel en la persistencia y en la superación de la pobreza en América Latina y el Caribe. Santiago de Chile: CEPAL. 2001. (Documento de Referencia DDR/1).

EVANS, P. Government action, social capital and development: reviewing the evidence on synergy. World development, v. 24, n. 6, p. 1119-1132, 1996.

FARAH, M. F. S. Parcerias, novos arranjos institucionais e políticas públicas no nível 
local de governo. Revista Brasileira de Administração Pública, v. 35, n.1, p. 119-144, jan./fev., 2001.

FARIA, C. A. P. A política da avaliação de políticas públicas. Revista Brasileira de Ciências Sociais, v.20, n.59, p. 58-169, out., 2005.

FERRARINI, A. V. Desenvolvimento Local Integrado e Sustentável: uma metodologia para políticas e programas de superação da pobreza. Interações, v. 13, n. 2, p. 233-241, jul./dez., 2012.

FIGUERAS, J. D. Capital Social, organizaciones de base y el Estado: recuperando los eslabones perdidos de la sociabilidad. In: ATRIA, R. et al. Capital social y reducción de I pobreza: en busca de un nuevo paradigma. Santiago de Chile: CEPAL/Universidad de Michigan, 2001. p. 247-302.

FUKUYAMA, F. Social capital and development: the coming agenda. SAIS review, v. 22, n. 1, p. 23-37, winter-spring, 2002.

Trust: The Social Values and the Creation of Prosperity. New York: Free Press. 1995.

GRINDLE, M. Good Enough Governance: Poverty Reduction and Reform in Developing Countries. Governance, v.17, n.4, p. 525-548, aug., 2004.

GROOTAERT et al. Questionário integrado para medir capital social. Grupo Temático sobre Capital Social/Banco Mundial, 2003. Disponível em: <http://empreende.org.br/ pdf/Capital\%20Social\%20e\%20Cidadania/ Question\%C3\%A1rio\%20Integrado\%20 para\%20Medir\%20Capital\%20Social.pdf>. Acesso em: 02 nov. 2013.

IBGE. 2006. Censo Agropecuário - 2006. Disponível em: [ http://www.ibge.gov.br/ home/estatistica/economia/agropecuaria/ censoagro/agri_familiar_2006_2/default. shtm]. [26/11/2013].
LOWNDES, V.; PRATCHETT, L. Public Policy and Social Capital. In: CASTIGLIONE, D.; VAN DETH, J. W.; WOLLEB, G. Handbook of Social Capital. New York : Oxford University Press, 2008. p. 677-708.

MANSURI, G.; RAO, V. Community-based anddriven development: A critical review. The World Bank Research Observer, v. 19, n. 1, p. 1-39, 2004.

MARTES, A. C. B. Redes e sociologia econômica. São Paulo: EdUFSCar, 2009.

MISOCZKY, M. C. Abordagem de redes no estudo de movimentos sociais: entre o modelo e a metáfora. Revista de Administração Pública, v. 43, n. 5, p. 1147-80, set./out., 2009.

MOHAMMED, A. K. Civic Engagement in Public Policy Making: Fad or Reality in Ghana? Politics \& Policy, v. 41, n. 1, p. 117-152, 2013.

NALLE JR., C. Desenvolvimento regional $\boldsymbol{e}$ políticas públicas: o caso do Projeto Amanhã da Companhia de Desenvolvimento dos Vales do São Francisco e Paraíba. Ribeirão Preto/ SP. Dissertação (Mestrado) - Universidade de São Paulo, Curso de Pós-Graduação em Administração, 2006.

NEIVA, E. R.; BRITO, M. J. P. Redes sociais e mudança em um grupo de produtores no planalto central. Revista Psicologia: Organizações e Trabalho, v.8, n.1, p. 5-22, jan./jun., 2008.

ORTOLANI, F. Políticas públicas e Capital Social: o caso dos municípios industriais e de serviços de São José do Rio Preto. Ribeirão Preto/ SP. Dissertação (Mestrado) - Universidade de São Paulo, Curso de Pós-Graduação em Administração, 2005.

PASSADOR, C. S.; PASSADOR, J. L. Apontamentos sobre as políticas públicas de combate à seca no Brasil: cisternas e cidadania? Cadernos Gestão Pública e Cidadania, v.15, n.56, p. 6586, 2010. 
PUTNAM, R. Comunidade e Democracia: a experiência da Itália moderna. 5 ed. Rio de Janeiro: Editora FGV, 2006.

Making Democracy work - Civic traditions in modern Italy. Princeton/USA: Princeton University Press, 1993.

SACHS, I.; LAGES, V. N. Capital social e desenvolvimento: novidade para quem? Conferência regional sobre Capital Social y Pobreza, 2001, Santiago. Anais... Santiago/ Chile: CEPAL/Universidad de Michigan, 2001.

SCHOLZ, C. W. Approaches to social capital: the emergence and transformation of a concept. American Sociology Association Annual Meeting, 98., 2003, Atlanta. Proceedings... Atlanta/USA: ASA, 2003.

SERAFIM, M. C.; ANDION, C. Capital espiritual e as relações econômicas: empreendedorismo em organizações religiosas. Cadernos EBAPE. $B R$, v. 8, n. 3, p. 564-79, set., 2010.

SIMAO, G. L.; SILVA, E. A.; SILVEIRA, S. F. R. Grau de cobertura do Programa de Aquisição de Alimentos (PAA) junto aos agricultores familiares do estado de Minas Gerais. Revista de Economia e Sociologia Rural, v. 52, n. 3, p. 533-548, 2014 .

SZRETER, S.; WOOLCOCK, M. Health by association? Social capital, social theory, and the political economy of public health. International Journal of Epideiology, v.33, n.4, p.650-667, jul., 2004.

TENDLER, J. Bom governo nos trópicos: uma visão crítica. Brasília: ENAP, 1998.

TITECA, K.; VERVISCH, T. The dynamics of social capital and community associations in Uganda: linking capital and its consequences.World Development, v. 36, n. 11, p. 2205-2222, nov., 2008.

TOMAS et al. Convenções, Capital Social e Desenvolvimento efetivo na agricultura familiar: o caso de Mato Grosso do Sul.
Organizações Rurais \& Agroindustrias, v.14 n.3, p. 409-425, 2012.

VARELA, C. A.; MATSUMOTO, C. Y. Política pública inovadora de geração de renda e desenvolvimento local: o caso da Câmara de Animação Econômica da Subprefeitura do Itaim Paulista (CAE-IT), São Paulo, Brasil. Revista de Administração Pública, n. 4, p. 1059-1079, jul./ago., 2012.

VASCONCELOS, A. M. A.; VASCONCELOS SOBRINHO, M. Desafios da parceria e participação como instrumentos de gestão coletiva para o desenvolvimento local na Amazônia. Encontro da Associação Nacional de Pós-Graduação em Administração, 35., 2011, Rio de Janeiro. Anais... Rio de Janeiro: ANPAD, 2011.

WAMPLER, B. Entering the State: Civil Society Activism and Participatory Governance in Brazil. Political Studies, v. 60, 341-362, 2012.

YEARY, K. H. K. et al. Religion, social capital, and health. Review of religious research, v. 54, n. 3, p. 331-347, jun., 2012.

ZUDEWICH, N.; NORRIS, D. 2005. National Experiences and International Harmonization in Social Capital. Measurement: A Beginning. Disponível em: [ http://www.tilastokeskus.fi/ sienagroup2005/douglas1.pdf]. [10/06/2013].

ZWICK, E. et al. Redes Interorganizacionais na Administração Pública Brasileira: Formação e Aspectos Culturais. Symposium, ed. 16, v. 8, n. 2, 30-39, jul./dez., 2010. 